\title{
тационарозамещающие технологии
} в здравоохранении Российской Федерации

\section{М.М. Бутарева}

ФГБУ «Государственный научный центр дерматовенерологии и косметологии» Минздрава России 107076, Москва, ул. Короленко, д. 3, стр. 6

Представлены данные о различных формах организации стационарозамещающей помощи в зарубежных странах

и Российской Федерации. Приводится опыт предоставления медицинской помощи по отдельным профиляям

в условиях стационарозамещающих технологий.

Ключевые слова: стационарозамещающие формы организации оказания медицинской помощи населению, дневной стационар, стационар на дому, дома сестринского ухода, отделения амбулаторной хирургии.

Контактная информация: butareva@cnikvi.ru. Вестник дерматологии и венерологии 2013; (4): 23-29.

\section{Tospitalization replacement technologies in the Russian Federation}

\section{M.M. Butareva}

State Research Center of Dermatovenereology and Cosmetology Ministry of Healthcare of the Russian Federation Korolenko str 3, bldg 6 Moscow, 107076, Russia

The article presents data on different forms of hospitalization replacement technologies in foreign countries and in the Russian Federation. The author describes an experience of administering medical aid according to individual profiles under the conditions of hospitalization replacement technologies.

Key words: hospitalization replacement forms of medical aid to the population, daytime inpatient department, home patient care, nurse care departments, outpatient surgery departments. 
В настоящее время одной из приоритетных задач, стоящих перед Правительством РФ, является оптимизация расходования бюджетных средств, в том числе и на здравоохранение. Постановлением Правительства РФ № 249 «О мерах по повышению результативности бюджетных расходов» от 22 мая 2004 г. была утверждена Концепция реформирования бюджетного процесса в Российской Федерации.

Для реализации разработанной программы Правительства РФ и Министерства здравоохранения РФ и оптимизации расходования бюджетных ассигнований медицинских организаций различных уровней актуальной проблемой является поиск новых экономически эффрективных моделей оказания высококвалифицированной амбулаторной медицинской помощи, в качестве которых можно рассматривать использование стационарозамещающих технологий [1, 2].

Во многих, преимущественно высокоразвитых, странах мира резкое сокращение расходов на стационарное обслуживание достигается за счет развития сети медицинских отделений краткосрочного пребывания [3, 4]. Кроме того, в таких странах, как США, Канада, Италия, Великобритания, в каждом клиническом случае реализация бюджетных ресурсов регламентирована специально действующим «Протоколом оценки обоснованности использования стационарной помощи» с четко сформулированными критериями отбора контингента [5].

В настоящее время в Европе представлены различные организационные формы оказания стационарозамещающей помощи. Они, как правило, занимают промежуточное положение между стационарным и амбулаторным типом обслуживания, а в ряде случаев носят смешанный характер.

В Италии, Франции, Нидерландах в качестве альтернативы традиционной больничной помощи для некоторых групп больных широкое распространение получили стационары на дому [6, 7]. Данная форма организации позволяет осуществлять обширный комплекс мероприятий по лечению, уходу и реабилитации больных по месту их жительства [5].

Здравоохранение Великобритании, являясь бюджетным и финансируясь примерно на 8\% валового национального дохода, постоянно испытывает нехватку больничных коек, в том числе для госпитализации больных с острыми заболеваниями. Подчас «листы ожидания на госпитализацию» насчитывают до 1 млн пациентов в год, что отражает чрезвычайную актуальность развития вариантов стационарной помощи населению [10-12]. Созданные в этой стране стационары на дому успешно функционируют на базе центров реабилитации для неврологических, травматологических, включая спинальных, больных, а также имеющих хроническую соматическую патологию, в том числе инвалидов и лиц престарелого возраста. Предоставление в стационарах на дому широкого спектра лечебных и реабилитационных мероприятий способствует не только ранней выписке больного из стационара, а в ряде случаев и предупреждению повторных госпитализаций. Таким образом, с помощью реализации данной модели достигается основная цель - снижение лечебной нагрузки на больничный сектор здравоохранения [8-10].

В США, Канаде и ряде других стран также накоплен богатый опыт функционирования дневных стационаров в условиях реабилитационных центров для пациентов ортопедотравматологического, хирургического и терапевтического профилей. Так, в дневном стационаре, созданном на базе реабилитационного госпиталя (штат Филадельфия, США), лечебный процесс, как правило, контролируется врачебными бригадами того же госпиталя. Доставляющимся в дневной стационар больничным транспортом пациентам проводятся необходимые диагностические исследования и комплексное лечение, включая процедуры восстановительной терапии. В условиях дневного стационара им также предоставляется однократное питание. После завершения обследования и лечения они доставляются домой транспортом учреждения [13, 14].

В Канаде дневные стационары - школы организованы для больных, страдающих сахарным диабетом. Основной целью, преследуемой при их создании, являлось, наряду со своевременным обследованием, ознакомление и реализация в повседневной жизни основ диетического питания, самоконтроля адекватности и коррекции получаемой инсулинотерапии. Пациенты дневного стационара имеют возможность получать консультации и необходимое лечение у специалистов смежного профиля клиники: кардиолога, дерматолога, гинеколога, невропатолога, офтальмолога, уролога, психиатра, стоматолога и др. Стоимость лечения в таком дневном стационаре почти в 2 раза ниже аналогичной в условиях круглосуточного стационара [15-17].

В 1978 г. в Германии на базе городской больницы Франкфурта одним из первых был организован гериатрический дневной стационар. И сегодня, в XXI веке, не только в Германии, но и в Швейцарии, Англии, Голландии, Швеции, США и других странах мира продолжают эффрективно фрнкционировать дневные стационары для больных старше 60 лет и способных к самообслуживанию. Нозологическая структура чрезвычайно разнообразна и представлена заболеваниями органов кровообращения, центральной и периферической нервной систем, включая инсульт, болезнями суставов, нарушениями обмена веществ (сахарный диабет), почечной недостаточностью, злокачественными новообразованиями, психомоторными нарушениями. Тесная интеграция с клиникой позволяет проводить этой категории больных, насчитывающих до 500 в год, современное обследование и лечение, сроки которых составляют в среднем до 30 дней [18-24]. 
В Канаде организованы центры амбулаторного обслуживания для выписанных из стационаров пациентов пожилого возраста. Выездная бригада в составе врача-геронтолога, среднего медицинского персонала, специалиста по трудотерапии, консультанта-психолога посещают престарелых пациентов на дому. В каждом конкретном случае индивидуально решается вопрос о целесообразности госпитализации или оказания им медицинской помощи и уходе на дому [17].

Долгое время больничные учреждения в Японии не подразделялись в соответствии с выполняемыми функциями, а значительная часть больничных коек использовалась в качестве социальных со средними сроками госпитализации 35-40 койко-дней. В настоящее время на медицинскую помощь лицам старше 70 лет государством расходуется до $40 \%$ годового бюджета здравоохранения. Большинство пациентов самостоятельно оплачивают те же услуги, в зависимости от страхового плана, лишь на 20-30\% их стоимости. Компенсацию разницы больничным учреждениям осуществляет местная администрация. В 1999 г. реализовалась 10-летняя стратегия укрепления здоровья и оптимизации социального обслуживания пожилого населения в рамках «Золотого плана». Согласно указанной программе, функция ухода за данным контингентом больных возлагалась на альтернативные медицинские учреждения: центры дневного ухода, учреждения, оказывающие помощь на дому, гериатрические больницы и др. Основной функцией последних является медико-социальное обслуживание лиц старше 65 лет. На повышенный спрос созданной по всей стране сети таких учреждений указывают листы ожидания пациентов, которым запланировано лечение в условиях дневных стационаров. Спектр представленных услуг, как правило, включает доставку больного микроавтобусом в клинику и обратно вечером домой, питание, уход, культурную программу, адаптированную к физическому и моральному состоянию больных, наблюдение курирующего врача и соответствующее лечение. Пациенты, имеющие медицинскую страховку, оплачивают лишь $10 \%$ от фактической стоимости всех услуг. Остальная сумма вносится страховой компанией. При необходимости длительного лечения сроки госпитализации и ухода не лимитированы и могут достигать в среднем 3-4 мес. Дневной стационар предназначен не только для больных, достигших 65-летнего возраста, но и более молодых пациентов, у которых установленный диагноз содержит патологию, ассоциированную с процессами старения организма [25-27].

Уже более 100 лет исполнилось хирургии дневного стационара, или однодневной хирургии. В 1909 г. Джеймс Николс (Великобритания) опубликовал результаты 10-летнего опыта проведения хирургических операций у детей в амбулаторных условиях.
Проведенный им анализ финансовых затрат 8988 вмешательств продемонстрировал десятикратную их эфрфективность.

Первый центр амбулаторной хирургии в США был открыт в 1969 г. В Аризоне. После принятия в 1986 г. Конгрессом США закона “О качестве амбулаторной хирургии» с перечнем в нем 100 разрешенных операций и специально сформулированного раздела, посвященного модернизации финансирования отрасли, количество операций, проводимых по методике «хирургия одного дня», резко возросло и достигло 33\%. В том же году в вооруженных силах США была разработана и утверждена инструкция по однодневной хирургии, содержащая уже более 400 видов разрешенных к проведению амбулаторных оперативных манипуляций и операций. В настоящее время в США насчитывается более 2000 хирургических центров, производящих ежегодно более 2,5 млн операций [28-34].

В высокоразвитых странах мира - США, Англии, Франции созданы дневные стационары для больных хроническими дерматозами. Комплекс лечебных мероприятий в них включает виды терапии, которые не могут быть оказаны в домашних условиях. Средний курс лечения в таком дневном стационаре составляет в среднем от 1 дня до 3-4 нед. У $80 \%$ выписанных больных достигается длительная - до 10 мес. и более ремиссия. Стоимость лечения в дневных стационарах составляет $1 / 3$ таковой стоимости в стационаре круглосуточного пребывания [35]. Таким образом, за рубежом представлено значительное разнообразие с развитой сетью эффективно действующих форм организаций стационарозамещающей медицинской помощи. Основной принцип формирования коечного фонда последних заключается в достижении максимальной эффективности работы койки путем высокого уровня ее специализации, целевого оснащения и интенсивного использования.

В Российской Федерации стационарозамещающие формы медицинской помощи были впервые созданы в 30-е годы прошлого столетия в виде ночных стационаров, стационаров выходного дня и дневных стационаров с режимом частичной госпитализации. Так, в 1930 г. на базе психоневрологической больницы им. П.Б. Ганнушкина был открыт первый дневной стационар, который выполнял функцию промежуточного звена между больницей и диспансером на базе лечебно-трудовых мастерских. В 1937 г. функционировало уже три учреждения такого типа.

В последующем аналогичные подразделения с терапевтическим, ревматологическим, хирургическим, пульмонологическим, стоматологическим и другими профилями создавались в Москве, Самаре, СанктПетербурге, Твери и других городах [36-38].

Различные стационарозамещающие модели медицинской помощи пациентам психиатрического профиля (также в качестве ночных стационаров, стационаров 
выходного дня (суббота и воскресенье), стационаров с режимом частичной госпитализации) начали свою лечебную деятельность в начале 70-х годов прошлого века. Используемый в них принцип частичной госпитализации позволял врачу, отпуская больного на определенное время домой, продолжать динамическое наблюдение и корректировку проводимой медикаментозной терапии. Подобная тактика ведения обладала высокой приемлемостью, так как «гасила в больном реакцию предубеждения и протеста, создавая атмосфреру доверия, сотрудничества с медицинским персоналом...». Такая фрорма стационарозамещающей помощи не подменяла функцию круглосуточных стационаров, а в известной мере гармонично дополняла их [39, 40].

Во фртизиатрии широкое распространение получили дневные и ночные санатории, организованные по типу дневных и ночных стационаров на базе противотуберкулезных диспансеров и медико-санитарных частей крупных промышленных предприятий [41, 42].

Начавшаяся в нашей стране в 1960-е годы активизация работы по созданию стационарозамещающих форм медицинской помощи позволила оценить позитивные стороны их деятельности, обосновать их медико-организационную целесообразность. Однако интерес к этой форме работы в последующие 20 лет был потерян. Нерешенность вопросов финансирования стала основной причиной снижения заинтересованности руководителей органов и учреждений здравоохранения в их развитии. Понятие «стационарозамещающие технологии» как фрорма оказания квалифицированной медицинской помощи населению в первичном звене отечественного здравоохранения появилось вновь в середине 1980-х годов [43].

С момента утверждения первого документа о создании дневных стационаров - приказа Министерства здравоохранения СССР от 16.12.1987 № 1278 «Об организации стационара (отделения, палат) дневного пребывания в больницах, дневного стационара в поликлинике и стационара на дому», развитие этих подразделений как при больничных, так и при амбулаторно-поликлинических учреждениях приобрело стремительные темпы [44].

Дневные стационары как фрорма улучшения качества медицинской помощи и расширение ее доступности населению нашли свое применение в хирургической службе, при травмах и заболеваниях кисти, при термических повреждениях $[45,46]$. В дальнейшем появились многочисленные научные труды, подтверждающие терапевтическую и экономическую целесообразность их дальнейшего развития.

А.Н. Сафиулов и соавт. (2004) представили структурный анализ нозологических форм дневных стационаров. Ими было показано, что почти половина (45,2\%) приходится на патологию сердечно-сосудистой системы, 12,5\% - на болезни органов дыхания, 9,9\% - на патологию системы пищеварения и менее
5\% - на заболевания и последствия травм опорнодвигательного аппарата [47].

Г.И. Корниловой (2006) проанализирована работа дневного стационара, развернутого на базе специализированного травматолого-ортопедического учреждения. Представлены показатели его деятельности в динамике, проведен сравнительный анализ объема оказания специализированной помощи, сроков и исходов лечения и временной нетрудоспособности у однотипных групп пациентов данного типа в сравнении с круглосуточным стационаром. Показаниями для направления в дневной стационар служили заболевания (33,8\%) и посттравматические поражения костно-мышечной системы (18,4\%), а также острая травма после оказания неотложной хирургической помощи, не требующая круглосуточного наблюдения (47,8\%). Тот фракт, что пациентами дневного стационара являлись люди молодого (20-29 лет) возраста $(27,8 \%)$, работающие $(58,3 \%)$ или учащиеся $(18,8 \%)$, подчеркивал высокую социальную значимость данной фрормы медицинской технологии. В выдаче документов по временной нетрудоспособности нуждались $41,5 \%$ пациентов. Обобщенный опыт работы дневного стационара лег в основу рекомендаций по технологии ведения больных с различной патологией опорно-двигательного аппарата, а результаты хронометража определили оптимальные штатные нормативы врачей травматологического дневного стационара [46].

В исследовании И.Н. Розовой и соавт. (1989) представлен имеющийся опыт организации работы дневного стационара для больных неврологического профриля, проведен анализ медицинской и социальной эффрективности. По данным авторов, лечение в условиях дневного стационара позволяло получить выраженный положительный эффект у 85\% больных. При этом после завершения лечения 84,7\% выписанных больных могли приступить к работе. Результаты проведенного авторами социологического опроса пациентов, завершивших лечение в дневном стационаре, показали, что 90\% респондентов предпочитают лечиться в условиях стационарозамещающих фрорм медицинской помощи. Наиболее веским аргументом при этом являлась возможность получить комплексное лечение в течение короткого времени (3-4 ч.) и после этого вернуться домой или на работу, не прерывать социальных связей, не испытывать сложности процесса госпитализации и неудобств больничных условий [48].

В литературе представлены многочисленные сведения об эффективности деятельности специализированных дневных стационаров для детей [49].

Так, в работах Н. В. Ерофеевой (2002) и М. А. Пеллер и соавт. (1991) подтверждена терапевтическая и экономическая эффективность лечебно-профилактических мероприятий у детей с хроническими заболеваниями органов пищеварения [49]. 
В исследованиях В.Е. Парилова и соавт. (1991), В.А. Рожко и соавт. (1992) отражены результаты работы дневных стационаров на базе детских ЛОРотделений, позволяющих проводить эффективное и качественное профильное обследование больных детей $[50,51]$.

А. Г. Баглаенко и соавт. (1992) показана возможность и эффективность выполнения у детей в возрасте от 6 мес. до 14 лет плановых операций в амбулаторных условиях при следующей хирургической патологии: грыжах передней брюшной стенки, пороках развития и заболеваниях наружных половых органов, доброкачественных опухолях небольшого размера и др. [52].

В работе Э.И. Дружининой и соавт. (1995) отражены детальные сведения о деятельности многопрофильного педиатрического дневного стационара. В нозологической структуре наибольший удельный вес имели болезни органов дыхания с преобладанием хронической очаговой инфекции ЛОР-органов (хронический тонзиллит, аденоидит, риносинусит и др.). Вторую по численности группу составили заболевания гастродуоденобилиарной системы, далее заболевания почек и кардиомиопатии. Терапевтический эффрект лечения в дневном стационаре оценен как улучшение в 88,8\% случаев и как выздоровление - в 7,2\%. Отсутствие положительной динамики состояния здоровья у $4 \%$ детей было обусловлено их преждевременной выпиской из дневного стационара по разным причинам. Изучение катамнеза детей, проведенное авторами, продемонстрировало улучшение состояния их здоровья и значительное снижение частоты обострений заболеваний [53].

Клинико-экономический анализ деятельности дневного стационара гастроэнтерологического профиля проведен в работе М.В. Черногоровой (2004). Автором установлено, что при равной клинической эффективности затраты на лечение больных с заболеваниями органов пищеварения в дневном стационаре гастроэнтерологического профриля были ниже, чем в круглосуточном стационаре. Разница на единицу эффективности на одного больного составила: 520 р. при хроническом панкреатите, 1436 р. - при язвенной болезни двенадцатиперстной кишки и 1062 р. - при язвенной болезни желудка на курс лечения. Стационарозамещающие технологии в гастроэнтерологии экономически обоснованы, более выгодны и не менее эфрфективны, чем традиционные виды помощи (круглосуточный стационар) [54].

В.А. Дмитриевым и соавт. (2010) анализировалась эффрективность использования стационарозамещающих технологий в организации медицинской помощи детям в условиях амбулаторно-поликлинического учреждения. На основании статистически достоверных данных предложены доступные и информативные критерии оценки результативности работы дневных стационаров всех типов [55].

В доступной литературе имеются единичные публикации по изучению эффективности работы дневных стационаров дерматовенерологического профиля. А.В. Гречко (2004) на примере больных хроническими дерматозами и сифилисом продемонстрирована высокая экономическая эффективность организации дневного стационара при больничном отделении кожно-венерологического диспансера (КВД). Общий экономический эффрект от рационализации лечебно-диагностического процесса, использования современных технологий на базе КВД на 90 коек, в том числе 40 койко-мест дневного стационара при больничном учреждении, составил до 40,2\% от общих годовых расходов на содержание коечного фронда КВД. Проведенные автором SWOT-анализ и анкетирование (социальные опросы) врачей, пациентов и руководителей здравоохранения показали высокую заинтересованность респондентов (опрошенных экспертов) в развитии этой организационной фрормы оказания дерматовенерологической медицинской помощи населению [56].

Последние годы, согласно данным официальной государственной статистики РФ, характеризуются наиболее высоким показателем заболеваемости дерматозами у лиц трудоспособного возраста, а также увеличением частоты встречаемости тяжелых форм дерматозов, резистентных к различным видам терапии. Хроническое, часто рецидивирующее течение обсуждаемой патологии требует предоставления высококвалифицированной специализированной, а в ряде случаев и высокотехнологичной медицинской помощи [57].

На современном этапе объем оказываемых лечебных мероприятий больным дерматозами предопределен нормативными правовыми актами и медицинскими документами Федерального органа исполнительной власти и базируется на основах доказательной медицины. Вместе с тем форма медицинских подразделений, в которых может быть оказана специализированная, в том числе и высокотехнологичная медицинская помощь данной категории пациентов, до сих пор четко не определена. Все вышеизложенное определяет актуальность и своевременность дальнейших исследований, предоставляющих научное обоснование экономической и терапевтической эффективности развития и использования в условиях модернизации здравоохранения стационарозамещающих технологий в области дерматовенерологии. [ 


\section{Литература}

1. Kucherenko V.Z., Tatarnikov M.A., Shamshurina N.G. Osnovnye napravleniya reformirovaniya rossiyskogo zdravookhraneniya na sovremennom etape. Ekonomika zdravookhr 2005; 8; 11-19. [Кучеренко В.3., Татарников М.А., Шамшурина Н.Г. Основные направления реформирования российского здравоохранения на современном этапе. Экономика здравоохр 2005; 8; 11-19.]

2. Shlyafer S.I. Pokazateli deyatel'nosti statsionarozameshchayushchikh form organizatsii meditsinskikh pomoshchi v Rossiyskoy Federatsii i rezul'taty priema godovykh statisticheskikh otchetov za 2008 god. Sotsial'nye aspekty zdorov'ya naseleniya: elektron. zhurn. 2009; (2). URL: http://vestnik.ru/content/ view/123/30/. [Шляфер С.И. Показатели деятельности стационарозамещающих форм организации медицинской помощи в Российской Федерации и результаты приема годовых статистических отчетов за 2008 год. Социальные аспекты здоровья населения: электрон. журн. 2009; (2). URL: http://vestnik. ru/content/view/123/30/.]

3. Komarov Yu.M. Meditsinskoe strakhovanie opyt zarubezhnogo zdravookhraneniya. Vestn gos sotsial strakhovaniya 2005; 1: 65-75. [Комаров Ю.М. Медицинское страхование: опыт зарубежного здравоохранения. Вестн гос социал страхования 2005; 1: 65-75.]

4. Martynchik S.A., Timchinskiy D.L. Sovershenstvovanie mekhanizmov oplaty statsionarnoy pomoshchi v sisteme dobrovol'nogo meditsinskogo strakhovaniya. Zdravookhr 2009; 5 : 67-74. [Мартынчик С.А., Тимчинский Д.Л. Совершенствование механизмов оплаты стационарной помощи в системе добровольного медицинского страхования. Здравоохр 2009; 5: 67-74.

5. Lang T., Liberati A., Tampieri A. European protocol. Int J Technol Asses Health Care 1999; 15: 1: 185-197.

6. Fittig E., Jacobi C., Backmund H. Effectiveness of day hospital treatment for anorexia nervosa and bulimia nervosa. Eur Eat Disord Rev 2008; 16: 5: $341-351$.

7. Forster A., Young J., Langhorne P. Systematic review of day hospital care for elderly people. BMJ 1999; 318: 837—841.

8. Siu A.L., Moshita L., Blaustein J. Comprehensive geriatric assessment in a day hospital. J Am Ger Soc 1994; 42: 1094-1099.

9. Forster A., Young J., Lambley R., Langhorne P. Medical day hospital care for the elderly versus alternative forms of care. BMJ 2004; 328: 1099.

10. Laroque P. Social protection and the over -75 s: What are the problems. Int Soc Security Rev 1978; 31: 3: 267-284.

11. Brocklehurst J.C. Role of hospital day care. BMJ 1973; 4: 223-225.13.
12. Hettiaratchy $P$. The UK's travelling day hospital. Ageing Int 2012; 1985: 10-11.

13. Brocklehnrst F. Geriatric Day Hospital. Age and Ageing 1995; 24: 2: 89

14. Fisher M.A., Grant W., Fisher M. Geriatric day hospital: the Sunnybrook experience. BSW CMA J 1981; 125: 447-476.

15. Eagle J., Guyatt G.H., Patterson C., Rcmrout $M$. Effectiveness of a geriatric day hospital. Health Care Institutions and Canada's Elderly: 1971-2031, suppl to Hospitals and the Elderly: Present and Future Trends. Long-range health planning branch. Dept of National Health and Welfare 1975. 17 Can Med Ass J 1991; 144: 699_-704.

16. Eagle J., Wall R., Strarford-Devai F., Deber R.G., Thompson G.G. Preliminary findings of the economic evaluation of an Ontario geriatric day hospital, in Restructuring Canada's Health Services System. How Do We Get From Here? Toronto: University of Toronto Press 1992; 285-299.

17. Wächtler C. 15 years of geriatric day care clinics in Germany. Psychiart Prax 2008; 139_142.

18. Seidler K., Garlipp P., Machleidt W., Haltenhof $\mathrm{H}$. Treatment concepts of day hospitals for general psychiatric patients: findings from a national survey in Germany. Eur Psychiat 2006; 21: 2: $110-117$.

19. Victoria B.C. Canada: National Evaluation of the Cost - Effectiveness of Home Care and Gerontology and Geriatric Research Centre-Sherbrooke University Geriatrics Institute 2001; 31.

20. Desrosiers J., Bravo G., He'bert R., Dubuc N. Reliability of the revised functional autonomy measurement system (SMAF) for epidemiological research. Age Ageing 1995; 42: 402-406.

21. IUGS. Re'partition des charges brutes par programme FIN-162, in Institut unversitaire de ge'riatrie de Sherbrooke. Que'bec, Canada: Sherbrooke; 1999.

22. Karterud S., Wilberg T. From general day hospital treatment to specialized treatment programmes. Int Rev Psychiatry 2007; 19: 1: $39-49$.

23. Desrosiers J., Marcus D. Economic evaluation of a geriatric day hospital: cost-benefit analysis based on functional autonomy changes. Age and Ageing 2003; 32: 53-59.

24. Ikegami N. Public long- term care insurance in Japan. JAMA 1997; 278: 19: 1310—1311.

25. Tacemira Y., Ishida H., Inone Y., Beck J.R. Common diaghostic test panels for clinical evaluation of new primary care outpatients in Japan. Clin Chem 1999; 45: 1752—1761.

26. Ogawa K. Outcomes Research of Home-Visit Nursing Care in Japan. Home Health Care Manag Pract 2006; 18: 4: 286-292.

27. Leithauser D.J. Early ambulation and related procedures in surgical management. Illinois Springfield 1946; 112: 149.
28. Wig J., Thakur J.S. Protecting health from climate change. The current status of day care surgery. Ind J Comm Med 2008; 33: 139-140.

29. Nicoll J.H. The surgery of infancy. Br Med J 1909; 2: 753.

30. Waters R.M. The down town anesthesia clinic. Am J Surg (Anesthesia suppl) 1919; 33: 71-73.

31. Newson C.D., Nathanson M.H., White P.E., Healy T.J, Cohen P.J. Anaesthesia for Day-stay (come and Go) surgery. Wylie and ChurchillDavidson's: A practice of Anaesthesia. Sixth ed. London: Edward Arnold 1995; 1363-1390.

32. Bapat R., Kanthari W., Rank S. Day care surgery in a public hospital set up. Bombay hospital J 2001; 249-252.

33. Henderson A.J., Wetchler B.V. Ambulatory surgery: Past, Present, and Future. Anesthesia for Ambulatory Surgery 1991; 1-27.

34. Cattaneo M., Thierry G., Betti R. Psoriasis and day hospital. Clinical and therapeutic considerations concerning 104 cases. Minerva Med 1986; 26: $1271-5$.

35. Skvirskaya G.P. 0 razvitii statsionarozameshchayushchikh form organizatsii i okazaniya meditsinskoy pomoshchi naseleniyu. Zdravookhr RF 2000; 1: 5. [Сквирская Г.П. 0 развитии стационарозамещающих форм организации и оказания медицинской помощи населению. Здравоохр РФ 2000; 1: 5.]

36. Rozova I.N. Deyatel'nost' dnevnogo statsionara gorodskoy bol'nitsy. Sov Zdravookhr 1989; 2: 54-57. [Розова И.Н. Деятельность дневного стационара городской больницы. Сов здравоохр 1989; 2: 54-57.]

37. Rozova I.N. Deyatel'nost' dnevnogo statsionara gorodskoy bol'nitsy. Sov zdravookhr 1989; 2: 54-57. [Розова И.Н., Шамракова Д.М., Евладова И.В., Краснова М.Н. Организация работы дневного стационара терапевтического профиля. Сов здравоохр 1989; 2: 54-57.]

38. Volovik V.M., Zenevich G.V., Koltun L.V. Dnevnye i nochnye statsionary kak tsentry chastichnoy gospitalizatsii psikhiatricheskikh bol'nykh (zadachi i funktsii na sovremennom etape) Tr Leningr NII psikhonevrologii 1976; 60-65. [Воловик В.М., Зеневич Г.В., Колтун Л.В. Дневные и ночные стационары как центры частичной госпитализации психиатрических больных (задачи и функции на современном этапе) Тр Ленингр НИИ психоневрологии 1976; 60—65.]

39. Belyaeva T.V., Kabanov M.M. Rezhim «chastichnoy gospitalizatsiì v psikhiatricheskom statsionare. Tr Leningr NII psikhonevrologii 1971; 59: 61—66. ГБеляева Т.В., Кабанов М.М. Режим «частичной госпитализации» в психиатрическом стационаре. Тр Ленингр НИИ психоневрологии 1971; 59: 61-66.] 
40. Skachkova E.I. Organizatsiya okazaniya meditsinskoy pomoshchi bol'nym tuberkulezom. M RIO TsNIIOIZ 2008. [Скачкова Е.И. Организация оказания медицинской помощи больным туберкулезом. М РИО ЦНИИОИЗ 2008.]

41. Lapina A.I. Organizatsiya bor'by s tuberkulezom v SSSR. M Meditsina 1969. [Лапина А.И. Opганизация борьбы с туберкулезом в СССР. М Медицина 1969.]

42. Starodubov V.I., Kalininskaya A.A., Shlyafer S.I. Statsionarozameshchayushchie formy organizatsii meditsinskoy pomoshchi. TsNIIOIZ MZ RF 2001. [Стародубов В.И., Калининская А.А., Шляфер С.И. Стационарозамещающие формы организации медицинской помощи. ЦНИИОИЗ МЗ РФ 2001.]

43. Prikaz Ministerstva zdravookhraneniya SSSR ot 16.12.1987 № 1278 «0b organizatsii statsionara (otdeleniya, palat) dnevnogo prebyvaniya $v$ bol'nitsakh, dnevnogo statsionara v poliklinike i statsionara na domu». [Приказ Министерства здравоохранения СССР от 16.12.1987 № 1278 «0б организации стационара (отделения, палат) дневного пребывания в больницах, дневного стационара в поликлинике и стационара на дому».]

44. Mukhin I.V., Polyakova K.A., Skvortsov K.K. Sokrashchenie srokov lecheniya bol'nykh $v$ khirurgicheskom statsionare. Klin khirurgiya 1995; 3: 17-19. [Мухин И.В., Полякова К.А., Скворцов К.К. Сокращение сроков лечения больных в хирургическом стационаре. Клин хирургия 1995; 3: 17-19.]

45. Kornilova G.I. Effektivnost' i perspektivy raboty dnevnogo statsionara $v$ usloviyakh travmatologo-ortopedicheskogo uchrezhdeniya. Travmatol i ortoped Rossii 2006; 2: 163. [Корнилова Г.И. Эфффективность и перспективы работы дневного стационара в условиях травматолого-ортопедического учреждения. Травматол и ортопед России 2006; 2: 163.]

46. Safiulov A.N., Karyakina M.N. Opyt raboty dnevnogo statsionara bol'nitsy v usloviyakh strukturnoy reformy na zheleznodorozhnom transporte. Zdravookhr 2004; 2: 24-27. [Caфиулов А.Н., Карякина М.Н. Опыт работы дневного стационара больницы в условиях структурной ресрормы на железнодорожном транспорте. Здравоохр 2004; 2: 24-27.]
47. Rozova I.N. Deyatel'nost' dnevnogo statsionara gorodskoy bol'nitsy. Sovetskoe zdravookhranenie 1989; 2: 54 - 57. [Розова И.Н. Деятельность дневного стационара городской больницы. Советское здравоохранение 1989; 2: 54—57.]

48. Peller M.A., Tel'main A.Kh. Effektivnost' provedeniya lechebno-profilakticheskikh meropriyatiy detyam s khronicheskimi zabolevaniyami organov pishchevareniya $v$ dnevnom statsionare. Pediatriya 1991; 1: 2-83. [Пеллер М.А., Тельмаин А.Х. Эффективность проведения лечебно-профилактических мероприятий детям с хроническими заболеваниями органов пищеварения в дневном стационаре. Педиатрия 1991; 1: 2-83.]

49. Parilov V.E., Zhuykova T.V. Effektivnost' DMVterapii i medikamentoznogo lecheniya v usloviyakh dnevnogo statsionara pri patologii limfoidnogo kol'tsa glotki u detey. Vopr kurortol fizioter i lech fiz kul'tury 1991; 6: 56— 57. [Парилов В.Е., Жуйкова Т.В. Эффективность ДМВ-терапии и медикаментозного лечения в условиях дневного стационара при патологии лимфоиддного кольца глотки у детей. Вопр курортол физиотер и леч физ культуры 1991; 6: 56-57.]

50. Rozhko V.A., Slobodskoy A.Yu. Opyt raboty dnevnogo statsionara detskogo LOR-otdeleniya Grodnenskoy oblastnoy klinicheskoy bol'nitsy. Zdravookhr Belorussii 1991; 9: 48-50. [Рожко В.А., Слободской А.Ю. Опыт работы дневного стационара детского ЛОР-отделения Гродненской областной клинической больницы. Здравоохр Белоруссии 1991; 9: 48-50.]

51. Baglaenko A.G., Popenko Yu.M. Khirurgicheskiy statsionar odnogo dnya - effektivnyy metod ozdorovleniya detey. M-ly VI Vsesoyuz konf det khirurgov 1988. [Баглаенко А.Г., Попенко Ю.М. Хирургический стационар одного дня - эфрфективный метод оздоровления детей. М-лы VI Всесоюз конф дет хирургов 1988.]

52. Druzhinina Z.I., Volkov S.A. Dnevnoy statsionar dlya detey - odna iz form povysheniya effektivnosti raboty ob"edinennoy bol'nitsy i polikliniki. Vsesoyuz konf L'vov 1983; 139140. [Дружинина 3.И., Волков С.А. Дневной стационар для детей — одна из форм повышения эффективности работы объединенной больницы и поликлиники. Всесоюз конф Львов 1983; 139_140.]
53. Chernogorova M.V., Belousova E.A., Gurov A.N. Sravnitel'naya kharakteristika kachestva lecheniya i kachestva zhizni gastroenterologicheskikh bol'nykh v usloviyakh nablyudeniya gastroenterologom i terapevtom. Eksperimen i klin gastroenterol 2004; 4 : 89-96. [Черногорова М.В., Белоусова Е.А., Гуров А.Н. Сравнительная характеристика качества лечения и качества жизни гастроэнтерологических больных в условиях наблюдения гастроэнтерологом и терапевтом. Эксперимен и клин гастроэнтерол 2004; 4: 89-96.]

54. Dmitriyev V.A. Current state and efficiency estimation of stationary substituting technologies in pediatric practice. Saratov Journal of Medical Scientific Research 2010; 1: 128-130. [Дмитриев В.А. Современное состояние и оценка эфффективности стационарозамещающих технологий в педиатрической практике. Саратовский научно-мед журн 2010; 1: 128-130.]

55. Grechko A.V. Analiz effektivnosti ispol'zovaniya koechnogo fonda kozhnovenerologicheskikh dispanserov. Materialy konferentsii «Mediko-sotsial'nye problemy sotsial'no-obuslovlennykh zabolevaniy» 26-27 maya 2004 g. M: GU TsNIIOIZ MZ RF 2004; 186-191. [Гречко А.В. Анализ эффективности использования коечного фонда кожно-венерологических диспансеров. Материалы конференции «Медико-социальные проблемы социально-обусловленных заболеваний» 26-27 мая 2004 г. М: ГУ ЦНИИОИЗ МЗ РФ 2004; 186-191.]

56. Znamenskaya L.F., Ya kovleva S.V., Volnukhin V.A., Pirogova E.V. Modern treatment methods for patients with psoriasis. Vestnik dermatologii I venerologii 2011; 1: 11-14. [Знаменская Л.Ф., Яковлева С.В., Волнухин В.А., Пирогова Е.В. Современные методы лечения больных псориазом. Вестн дерматол и венерол 2011; $1: 11-14$.

М.М. Бутарева — к.м.н., зав. дневным стационаром ФГБУ «ГНЦДК» Минздрава России, Москва 